\title{
VERSITA
}

$10.2478 / v 10284-012-0004-0$

\section{TRADITIONAL TYPE IN THE DIGITAL ERA}

\author{
SILVIA WEINZETTELOVA
}

The rapid transformation of print to digital media has been triggered by the technological development of past few decades. With the invention of personal computers and graphical user interface (GUI) to make interaction between the user and the machine possible, typography for UI has become one of the most challenging parts of user experience development.

Nowadays, the statistics show that the modern society is about to reach yet another significant milestone - a full switch towards mobile technology. Smartphones, iPhones, and tablets have been dominating the market for the past few years. However, the predictions show that in the next few years, sales of such devices are going in any other direction but upwards.

This paper explores the predestination of traditional typefaces nowadays, in the era of digital technology. The author argues that the traditional typefaces are struggling to stay relevant in a world where most media is viewed on electronic screen devices. For the research, mostly secondary sources were used which may also pose a limitation to the study. Primary data would have been valuable, especially in the area of semiotics, emotions, and subjective comprehension of typography and UI.

The first part of this paper briefly reviews the history of typography and the ways how the traditional type-faces had been modified in order to ensure high readability and legibility.

Semiotics of type, as well as the importance of positive emotional response to UI and UX, are discussed in the second part, highlighting the important patterns in the user's comprehension and emotional responses.

In the third place, the shift towards the "mobile first" approach is emphasised, and the importance of adopting the appropriate methods and techniques which would ensure the optimal representation on in-formation on small screen handheld devices is justified; the problems caused by type scaling and reading patterns, screen resolution, pixel representation, and back-lit environment are identified. Furthermore, the optimal characteristics of screen fonts are explained.

Last but not least, the present and future of typography on small screens is discussed. 
While the individual symbols, glyphs, alphabets, words, and languages started to form thousands of years ago, it was not until the 15th century when European typography reached one of its most significant milestones. The first and supposedly the most notable step in the development of the type was the invention of movable type, which is usually contributed to the German goldsmith and printer Johann Gutenberg, around the mid-15th century. "The true origins of this lay much earlier though, with the forerunner of Gutenberg's revolutionary system being invented by Bi Sheng in China between 1041 and 1048. Further refinements were made during the Goryeo Dynasty of Korea by ChweYun-Ui in about 1234, where metal was first used instead of brittle clay or easily damaged wood"(Ambrose e Harris, 2006: 12).

Initially, the first type of text to be reproduced by the movable type printing press was laid out in Blackletter, the style of type also known as Gothic or Old English, which is characterised by a complex, ornate quality to its thick to thin strokes. However, due to its decorative nature and limited readability, Blackletter was soon substituted by a different class of type.

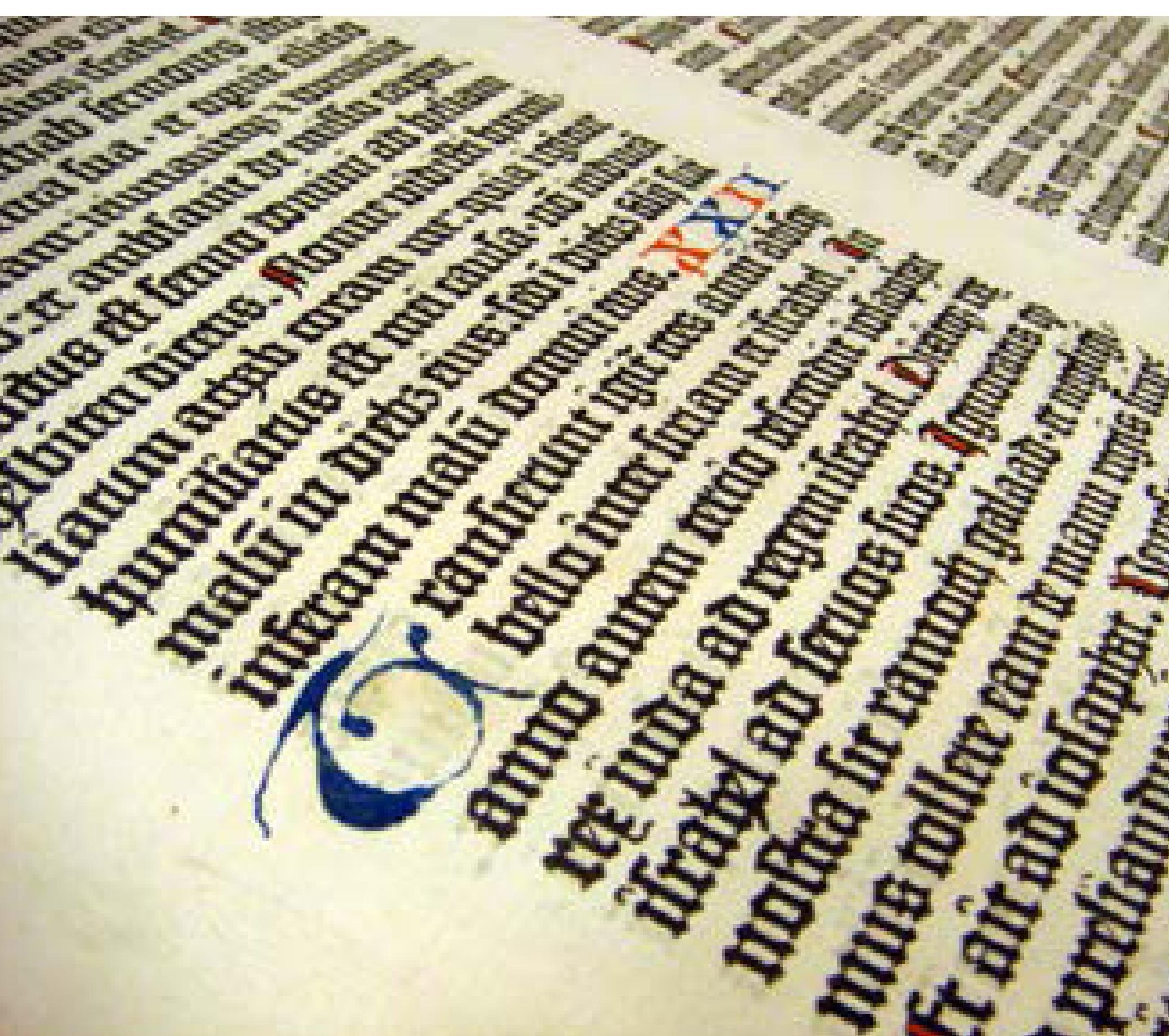


After the invention of metal movable type, France, Italy, Great Britain, and Holland became the centres of constant typographic progress. Thus, it is hardly surprising that the first independent type foundry was founded in Paris, France, in 1530. Claude Garamond, the founder of the aforementioned type foundry, quickly popularised the so-called Old Style typefaces, the lighter and more legible versions of the ones classified as Humanist (Fig. 2).

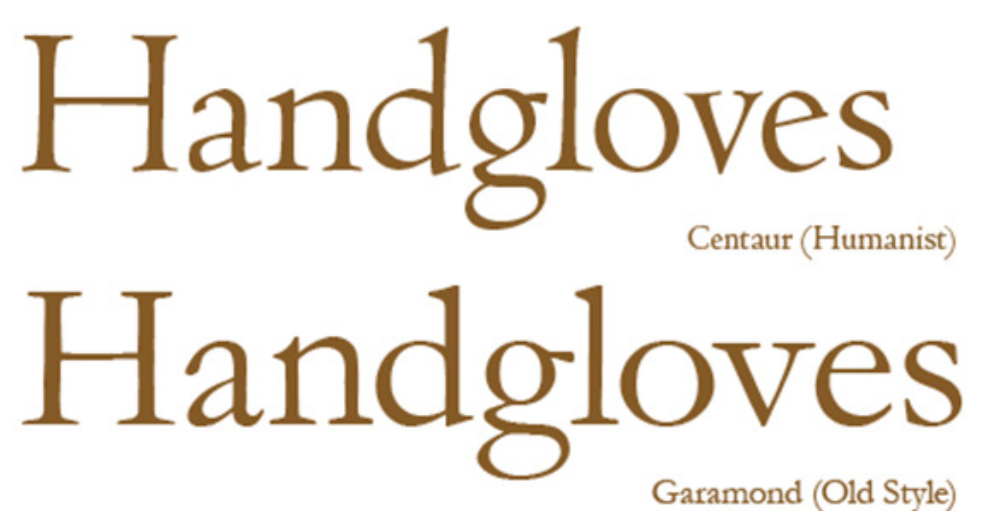

Figure 2: Visual comparison of Humanist and Old Style typefaces.

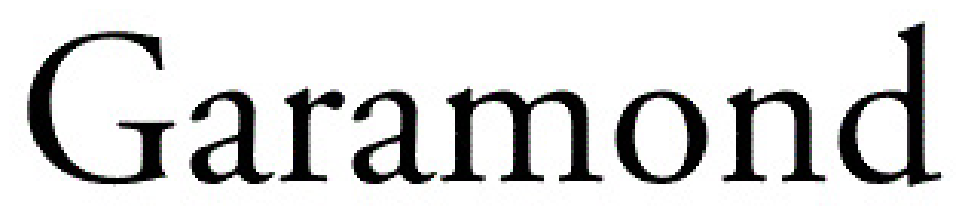

\section{Garamond}

\section{Garamond}

Figure 3: Visual comparison of three different versions of Garamond, (from top to bottom). Adobe Garamond, Garamond Premier, and Original Garamond.

Throughout the centuries, the original Garamond typeface became a foundation stone to number of versions; some of which were based solely on Claude Garamond's design, the others on Jean Jannon's, and inevitably, new revival versions like Adobe Garamond and ITC Garamond came into existence. ITC Garamond "was designed in 1977 by Tony Stan for ITC. Very loosely based on the forms of the original sixteenth-century Garamond-era work, this version has a taller x-height and tighter letterspacing, two elements that were very popular in New York advertising design during the 1970s"(Linotype GmbH, no date).

While Garamond's popularity for print and other non-digital use might seem immense, especially thanks to its optimal legibility and readability, traditional serif typefaces may appear to be scarcely used across the online media. 
In the 18th and 19th centuries, the rapid industrial growth resulted in the Industrial Revolution, bringing "mechanisation that allowed printing to speed up, photo-engraving which replaced handmade printing plates and line-casting machines that revolutionised typesetting and allowed for ever-ever-increasing levels of detail and intricacy. The use of points as the measurement system was cemented during this period" (Ambrose er Harris, 2006: 34). The 18th century was an era of stylistic innovation. In 1737, William Caslon established his type foundry, and thanks to his valuable contribution to the development of typography in Britain, he has been regarded as the father of British typography since.

Later, the French and Italian contemporary typographers "refined and modernized typography as they stepped further from their calligraphic origins. While Baskerville was the pioneer of the neoclassical style letterform, the most extreme forms were developed by Firmin Didot and Giambattista Bodoni" (Designhistory.org, 2000). Both Didot and Bodoni inclined towards high visual contrast within the glyphs, turned away from slanted serifs, and preferred a vertical axis for their glyphs.

In 1884, Ottmar Mergenthaler introduced a revolutionary typesetting machine. "The linotype machine used a keyboard device to operate lines of cast type, which was then pressed into a mold and printed" (In-dependent Television Service, 2008). However, phototypesetting, a typesetting method using the photographic procedures in order to produce columns or scrolls of text, soon replaced the mechanical typesetting devices. The popularity of this method reached its peak in the 1960 s and became a standard in the industry.

With the blossom of the International Typographic Style in the 1950s, the graphic designers focused on positioning the elements according to a grid system and the use of very legible sans serif typefaces such as Akzidenz Grotesk, the forerunner of Helvetica. The type was usually the most prevalent and significant element of the design piece. Typefaces like Max Miedinger's Helvetica, Adrian Frutiger's Univers and Frutiger, and Eric Gill's Gill Sans all offered the same features - legibility and readability, cleaniness, rationality, minimalism, uniformity, and neutrality. With the arrival of computers, the highly legible and emotionally versatile type- faces became a cornerstone of the first screen fonts which are discussed on page 15.

\section{TYPE AS A SIGN}

Arguably, type can be considered as an image on the premise that the text is a visual object. If the text is deconstructed into sentences, words or even individual glyphs, every such piece carries individual visual and semiotic characteristics.

The roots of semiotics, the study of signs used in differing environment and context, reach back to ancient Greece and are most often linked with the philosophical work of Hippocrates, Plato, and Aristotle. However, only two major directions, one of the American philosopher Charles Sanders Peirce (1839 - 1914) and the other one of Swiss linguist, Ferdinand de Saussure (1857 - 1913) will be discussed in this paper.

In regards to typography, Saussare's pragmatic concept is based on the assumption that type exists solely to represent vocal communication. According to his theory, a sign is a combination of two equal parts, "the 'signifier' (or 'signal') and 'signified' (or 'signification'), where the 'signifier' is the signs physical presence, and the 'signified' is the concept evoked in the mind of the receiver"(Brownie, 2009: 3). When this notion is applied to type, the visual aspect of a sign (a word) is inconsiderable. Thus, it can be said the visual appearance of the signs is completely overpowered by their meaning. 
Peirce, on the other hand, argues that a sign is composed of three parts, 'representamen', 'object' and 'interpretant'. In this model, the 'representamen' is the representational object or form, equating to Saussure's signifier, the 'object' is the thing to which is directly represented, and the 'interpretant' is the meaning that is achieved once the sign has been 'evaluated' by the audience' (Brownie, 2009: 4).

From a semiotic and linguistic point of view, any symbol, whether typographic or not, carries a certain value and meaning. Spitzmüller (2007) supports this notion by stating that typography "has the potential to refer to a specific value system and thus can be used to express values, attitudes, associations, etc. In other words: typographic elements might be used as signs". This claim is supported by Eco's (1979: 179) point that "signs [... ] possess a certain quality of material uniqueness (e.g. a word which someone speaks or which is handwritten)". In the case of typography, the material value of a word is demonstrated not only by the physical features (such as colour of ink, size, and so on) but also by its visual form - font choice or visual style.

\section{The importance of material quality to the textual sign indicates that the symbolic perception of a word can be strengthened by using a specific style of a typeface or font}

According to Roland Barthes (1915 - 1980), every sign can be analysed according to three different orders. First, denotation is a literal description of a sign. Secondly, connotation is a secondary meaning which relies on "cultural or historical contexts, contexts of both the image and the viewer"(Carroll, no date). Last but not least, a third level of meaning - a myth - expands the area of possible connotations. Barthes' myth can be defined as a collective historical and cultural background which influences the viewer's subjective understanding of a sign. The possible amount and content of the connotative meaning is therefore unpredictable.

It can be concluded that the form of a written or typed word can influence the overall comprehension of a sign, especially if the visual aspect of the sign articulates the 'signified' faster, or together with the verbal aspect, helps the viewer to comprehend the message in a specific way. However, the presence of Barthes' myth leaves the connotative meaning open to the collective background and knowledge of the society, as well as to the subjective experience and judgment of a viewer. The importance of material quality indicates that the symbolic perception of a word can be strengthened by using a specific style of a typeface. Thus, the font choice is extremely important in order to evoke an optimal viewer response. Furthermore, a positive emotional response to design, looks and overall feel of the piece of work, be it printed material, web experience or native application, is extremely important for a message to be clearly communicated and well understood by a viewer.

\section{THE UPRISE OF MOBILE TECHNOLOGIES}

In 2009, Meeker, Devitt e Wu (2009) in their talk at the Web 2.0 Summit stated that "usage of mobile devices on IP-based networks should surprise to upside for years to come and bandwidth suppliers (telcos / cable) face serious challenges in managing incremental traffic. Smartphones were boldly predicted to out-ship the combined global market of laptop, desktop and notebook computers in 2012. They did so in the last quarter of 2010 [... ] - two years earlier than predicted"(Wroblewski, 2011: 7). "It is expected that by 2013 , the number of heavy mobile data users will reach one billion"(Wroblewski, 2009). 
In spite of different smart phone brands having different screen and browser (both web and OS-based, in-built one) features, the current wave of app-development seems to focus on the three most popular mobile operating systems: iOS, Android, and Windows Mobile. In December 2011, Google announced that they had reached a milestone of 10 billion downloads from Android Market (Fig. 4). Earlier in June, Apple had celebrated 15 billion downloads from the App Store.

The rapid growth and development of mobile technologies call for a prompt switch towards the 'mobile first' approach to web and UI design.

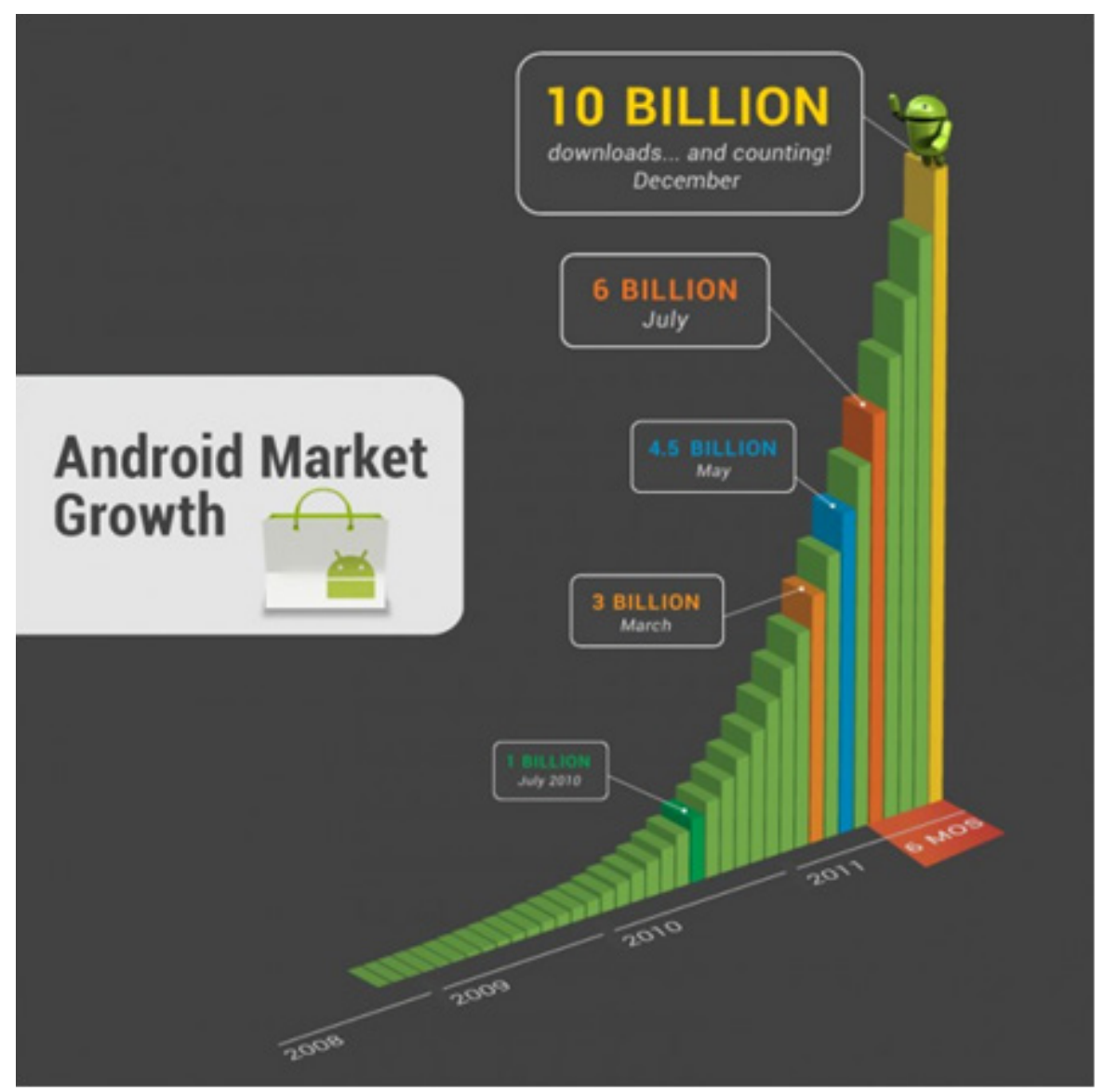

Figure 4: The number of downloads from Android Market has been rapidly increasing.

\section{TECHNICAL LIMITATIONS:}

\section{SCREEN RESOLUTION AND PIXEL RENDERING}

The boom of digital technologies was triggered in 1983 "when Apple introduced the Apple Lisa, the first desktop computer with a graphical user interface (GUI)"(Hillner, 2009: 79). Followed by Apple Macintosh only a year later, digital typography did not only meet its first important milestone but also a series of setbacks. Apple Macintosh's screen was 9 inches wide; therefore slightly smaller than today's iPad, with a resolution of only $512 \times 342$ pixels. Low screen resolution combined with poor pixel representation, resulting in a mere $68 \mathrm{PPI}$ (or 4,680 $\mathrm{PPI}^{2}$ ) and $0.3713 \mathrm{~mm}$ dot pitch, did not allow the use of sophisticated serif type. Compared to the Apple iPhone 4 which is equipped with approximately 330 PPI (or 108,669 PPI2) and dot pitch of $0.0771 \mathrm{~mm}$, the graphic representation of visual elements in the first Apple Macintosh was extremely limited. 


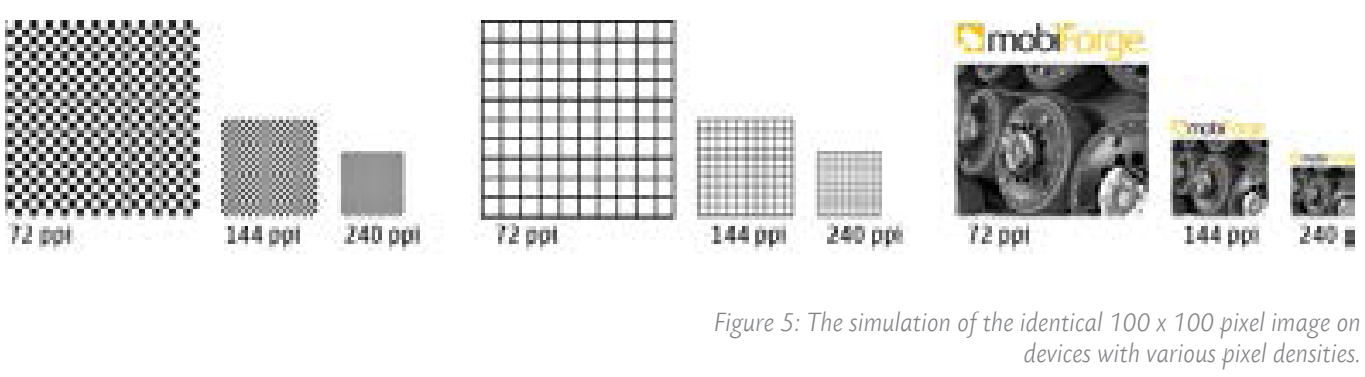

Another problematic aspect of on-screen reproduction of traditional serif typefaces is scaling. With the invention of metal movable type, the moulds for the various sizes were individually customised in order to maintain optimal readability and legibility in print. Therefore, a serif typeface would in smaller sizes consist of thicker strokes, serifs, and slightly increased kerning. "When printed, the serifs on typefaces are only a tiny percentage of the typeface's design. But on screen, in order to display the serifs using the limited number of available pixels, they take up a much bigger proportion of the information than they do on a printed page. Serifs should be small things--but on screen they become big--no longer visual cues but noise--distracting chunks of interference" (Will-Harris, no date).

On the condition that text of the same typeface, size, width, and leading is displayed on screen and in print, side by side, the on-screen version would presumably be less legible. First of all, that is due to the fact that a modern laser printer is able to reproduce a document at a resolution up to $2400 \mathrm{dpi}$, as compared to a screen resolution of 72 or 96 dpi.

The modern approach to digital typesetting allows the designers to scale the text pari passu, or in other words, proportionately. The infinite scalability is caused by the fact that single glyphs are stored as Bézier curves. Assuming that a glyph of a vector-based font is digitally re-sized, the form itself shall not demonstrate any distortion or malformation (Fig. 6).

\section{a}
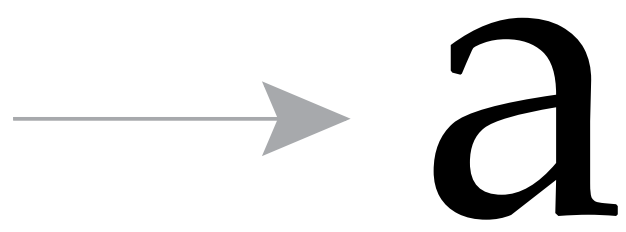

Figure 6: A font stored in Bézier curves does not show any distortion when enlarged.

However, a font is not displayed in vector format in the web and UI environment. On-screen font rendering from a vector format into raster may cause significant changes to the shape and form of a glyph, as illustrated by Fig. 7. "The translation of a font's outlines into pixellated text of varying quality, consistency, and sharpness is not straightforward. It involves both a font and a rendering engine, and only so much can be controlled by type designers and web designers"(Adobe Systems Incorporated, 2009).

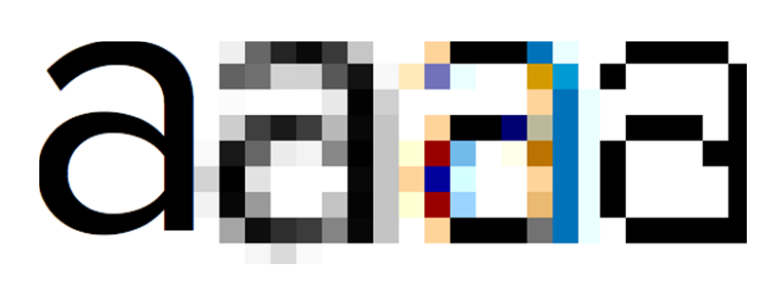

Figure 7: Rendering of a lowercase "a"by three rendering engines. 
Additional techniques have been developed in order to avoid substantial changes in the form of glyphs. Anti-aliasing is a font-smoothing rendering method "uses partial opacity to emulate smooth curves of the glyphs. As the final result, the shape of glyphs is more true to the type's design"(Szafranek, 2009)(Fig.8). Anti-aliasing is dependent upon hinting (Fig. 9), a technique which uses mathematical algorithms to determine not only the exact position of a pixel, but also to determine what areas of a glyph need to be smoothed. However, anti-aliasing is not being used for small font sizes due to the 'blurriness' it causes.

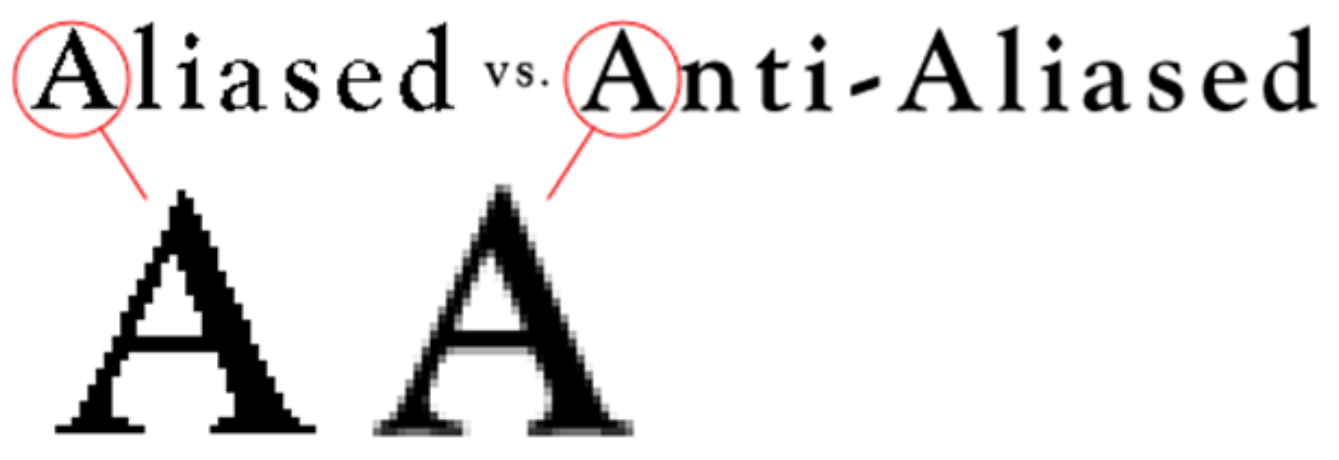

Figure 8: Comparison of an uppercase " $A$ ", aliased and anti-aliased.

Hinted Rendering
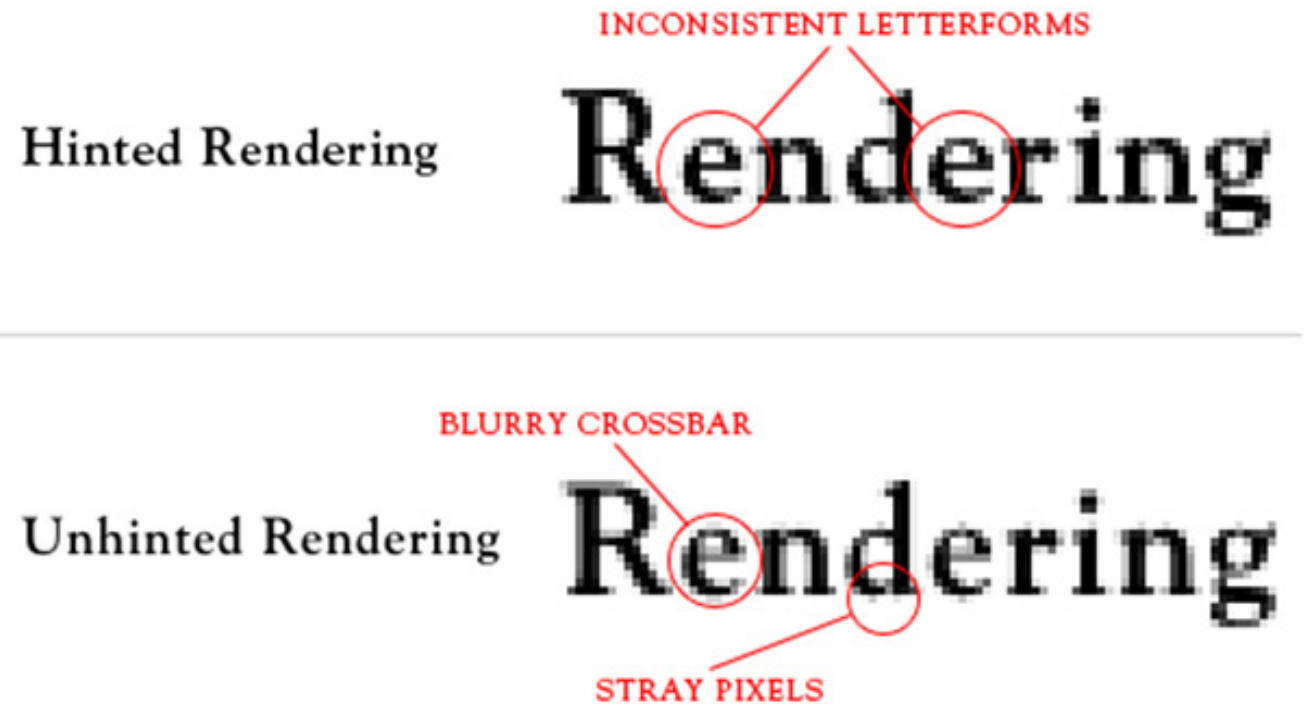

Figure 9: Visual comparison of differences between hinted and unhinted rendering of a typeface.

Sub-pixel rendering method, a technique which involves a subdivision of RGB pixels, smooths the edges by distributing red, green and blue sub-pixels along the ragged edge (Fig. 10). "Software capable of using subpixels can effectively emulate horizontal resolution that is 3 times bigger than normal resolution, e.g. $3072 \times 768$ instead of $1024 \times 768$. Subpixels are small enough to be indistinguishable to a human eye, but can be identified with a magnifying glass"(Giannattasio, 2009). 
suswatatume Render

Subpixel Rendering

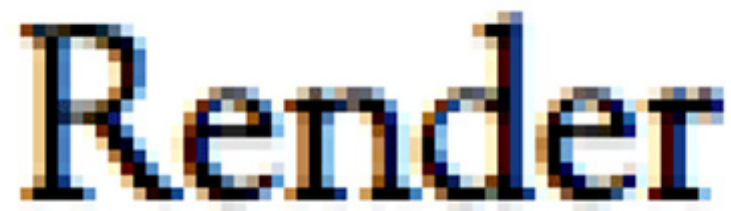

Figure 10: Standard rendering causes greyscale pixels to be added, while subpixel rendering creates pixels of different colour shades.

Current methods of pixel rendering generously vary across operating systems and browsers. However, operating systems and browsers using subpixel rendering engine Quartz, such as OSX, seem to render the fonts more accurately than Windows-based ClearType engine is able to represent. Therefore, Quartzrendered fonts lose less detail and are significantly closer to the original type designs.

\section{BACK-LIT ENVIRONMENT}

Another factor to impact the text legibility is the back-lit environment it appears in. "Since a lit monitor is much brighter than the reflective light of paper, the contrast between black and white on a monitor is much greater than it is on printed materials. To promote readability, screen typography should have enough contrast to be legible, but not so much contrast as to unnecessarily irritate the viewers' eyes"(Rabinowitz, 2006: 260).

It is suggested that on-screen text should be laid out as in reverse, using black background and white colour of the text. Taking into account the basic colour theory rules, black, grey, and white are considered to be neutral colours. However, as seen in Fig. 11, "high levels of contrast can cause an optical dazzle effect. High contrast can also cause type glow, which occurs when the brightness of a background permeates the edges of darker or duller letterforms, making them appear thinner. Type glow can also happen when the brightness of letterforms seems to overflow into a darker or duller background, creating an optical aura that makes the letters seem to glow"(Rabinowitz, 2006: 261).

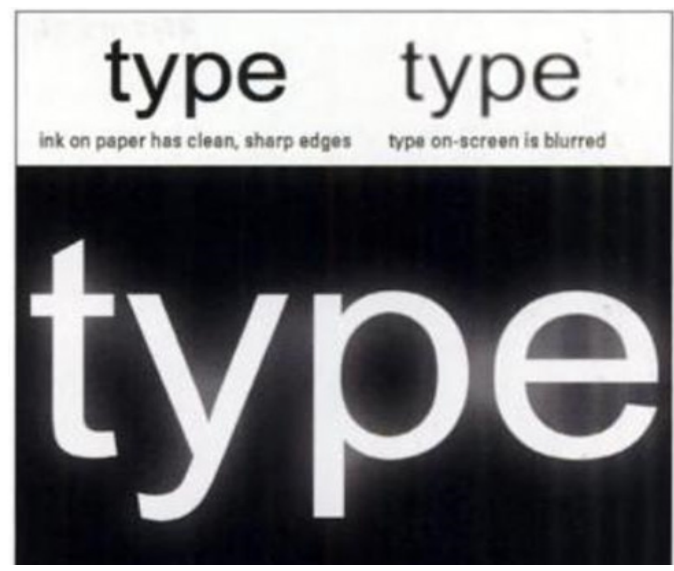

Figure 11: Type glow
Frazier (1920: 13) states that "recognition of letters may be difficult if there is not in them an adequate amount of white space, as for instance in the center of the "o," the loops of the " $p$ " and "b," the spot at the top of the "e" and at the bottom of the "a," and between the stems of the " $m$, " " $n$, " " $h$ " and " $u$ ". It is important to note that according to some studies, a human eye does not focus on reading individual letterforms but on comprehending general shapes and forms, mostly by processing the white space around the glyphs. 
A revolutionary approach to reading comfort emerged with the successful development of digital link technology. "E Ink is a proprietary technology of a company called E Ink Corporation. E Ink is considered a type of electronic paper, which is a technology class designed to mimic the look of real paper and print on an electronic screen"(Zarley, 2011: 17). Unlike the liquid crystal displays, E Ink-based eBook readers such as Amazon Kindle, Barnes e Nobble Nook, and Kobo eReader do not reflect light which notably improve the legibility. Furthermore, the displayed text is less limited in terms of upholding to the standardised set of typographic rules.

\section{MARK-UP LANGUAGE AND BROWSER SUPPORT}

The pre-determined options for control over the web typography are still limited. The latest version of Cascading Style Sheets (CSS 3), and CSS Fonts Module Level 3 in particular, specify a wider range of font properties than the older versions. The constraints stem from the fact that in essence, CSS's main purpose was to provide control over the style of web elements and not the layout. Additionally, the cross-browser support of CSS 3 varies greatly, and therefore scripts, hacks, and other complementary techniques are being used to overcome the existing restrictions.

In addition to the aforementioned lack of control over the typographic aspect of web layout, there is an extremely scarce number of effective and legible screen fonts. Verdana (Fig. 12), Georgia, and Trebuchet MS (Fig. 13), both designed specifically for display on screen, contain the most important characteristics which enhance their readability and legibility on screen. They were "most popular in the 90's and early 2000's. Of late, Helvetica [... ] is gaining huge popularity"(Kolman, 2009: 4).

Benevolent $\mathrm{x}$-height, wider tracking, relatively wide space within the glyphs, and distinctive letterforms significantly add towards legibility of the text, even if displayed in small sizes.

\section{Verdana \\ WIDE PUNCH WIDTH}

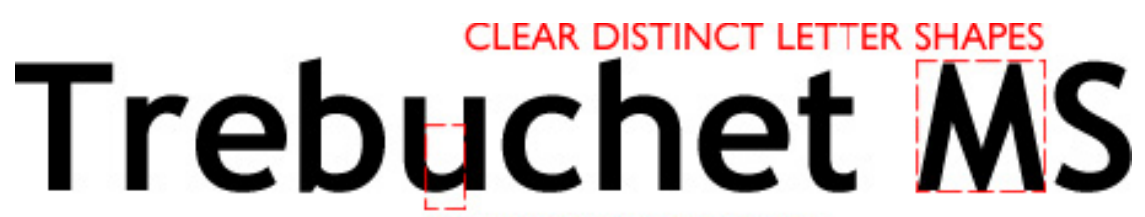

WIDE PUNCH WIDTH

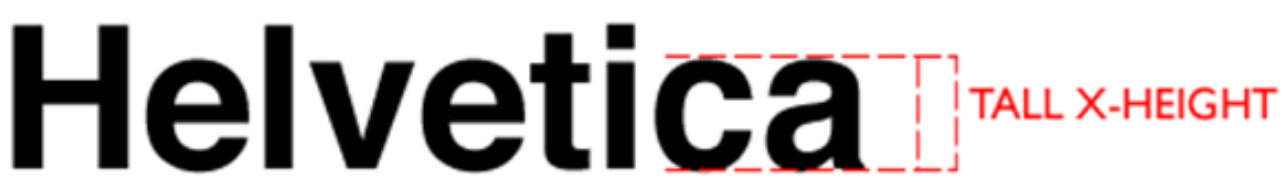

Figure 12, 13, 14 (from top to bottom): Desired characteristics of a screen font demonstrated with Verdana, Trebuchet MS, 
While Helvetica (Fig. 14) was not initially designed for the screen, the aforementioned characteristics have contributed towards its popularity as a screen font. In all three cases, the ratio of white and occupied space is notably similar. Therefore it can be concluded that nearly any typeface with relatively tall $\mathrm{x}$-height, wide tracking, wide punch width, and relatively thick distinctive glyphs can potentially be a successful screen font, if adhering to pre-existing fundamentals of typographic layout. Consequently, the designers should focus more on designing screen fonts because larger numbers of computer users spend their entire time in front of a screen and never (or seldom) print anything. So it became obvious to us that this was a reversal of priorities -- we should not approach this as doing printer fonts adapted for the screen, we should design them as screen fonts from the outset. The printer fonts are secondary in this case" (Byrne, 2003: 14).

\section{USER'S INTERACTION:}

\section{READING PATTERNS}

In 2006, the Nielsen Norman Group conducted a study on web reading patterns. For this purpose, an eyetracking device was used. It was discovered that the most prevalent way of reading a website sequentially resembles a F-letter, when a viewer starts reading with two horizontal eye movements across the top area of the website, which are then followed by a vertical movement towards the bottom of a browser window or a website.

Unfortunately, very little is known about the reading patterns on small screen devices and concerns "whether information gathering from such small screens results in a cognitive trade-off in subsequent performance" (size-on-small-screens) have been raised. Although the smartphones and tablets ordinarily offer a landscape view option, large font size causes an increased need for scrolling, which has proven detrimental to the cognitive comprehension of the text. While it is important to minimise the need for scrolling, the user should also be given an option to resize the text according to his/her needs.

Reading patterns on small screen devices are significantly dependent upon the design of the website or application itself. Mobile versions of websites tend to adhere to designs which support the F-letter reading pattern by implementing a horizontal menu and logo at the top. This trend is clearly shown on Jonathan Snook's website (Fig. 15).

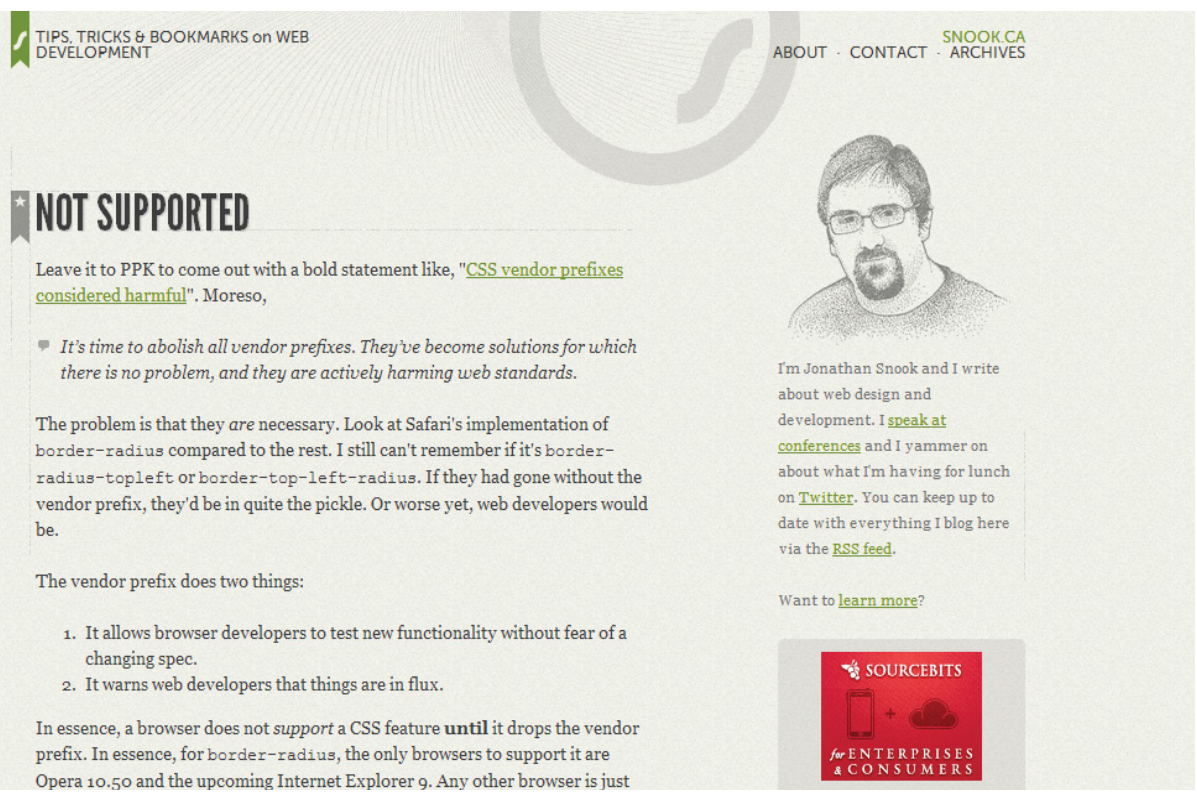




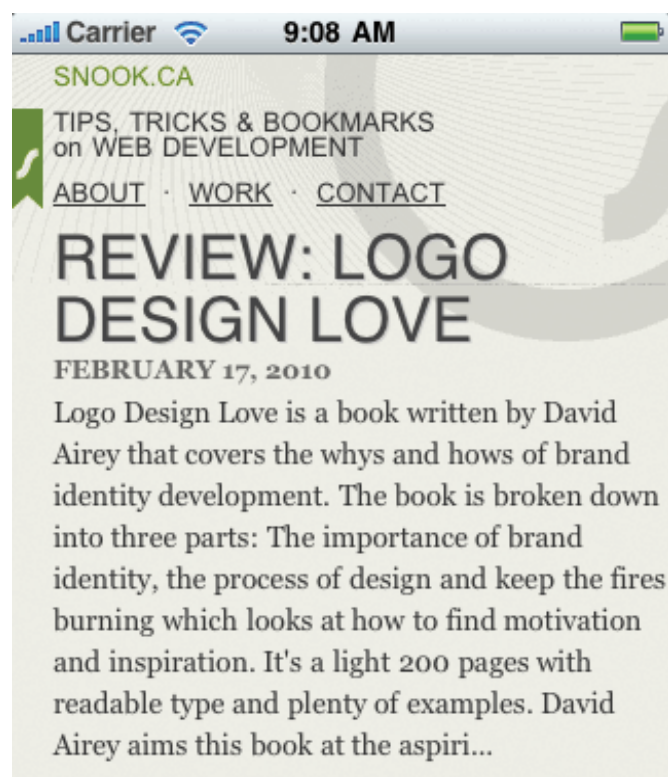

READ IT ALL »
In the mobile version (Fig. 16), the hierarchy of elements is essentially maintained; the main emphasis is put on dynamically-generated text (blog entries), while the sidebar with stagnant information and advertisements has been removed.

Another notable change is to be seen in the title of the article. Although the original web version uses dynamic text replacement technique, the mobile version uses web-safe fonts for all the typographic elements. Such an approach may be caused by inability to render alternative fonts in mobile versions properly, or the desire to maximise the readability and legibility of all text on small screens.

The tendency to emphasise dynamically-generated text is prevalent in web-based applications and mobile websites - a website which contains CSS styling especially for mobile devices.

Figure 16: Mobile version of SNOOK.CA, shown on an iPhone screen.

\section{EWMOTION IN INTERACTION}

As any aspect of design, the user's interaction with $\mathrm{UI}$ and displayed information are affected by their emotion-based perception. According to Norman (2002), "emotion is one of the strongest differentiators in user experience namely because it triggers unconscious responses to a product, website, environment or interface. Our feelings strongly influence our perceptions and often frame how we think about or refer to our experiences at a later date."

While the importance of overall user experience and functionality cannot be undermined, aesthetics and visual form of a design piece play a crucial role in forming a positive bound with the user. The strive for a pleasurable experience can be well explained by the Maslow's Hierarchy of Needs (Fig. 17).

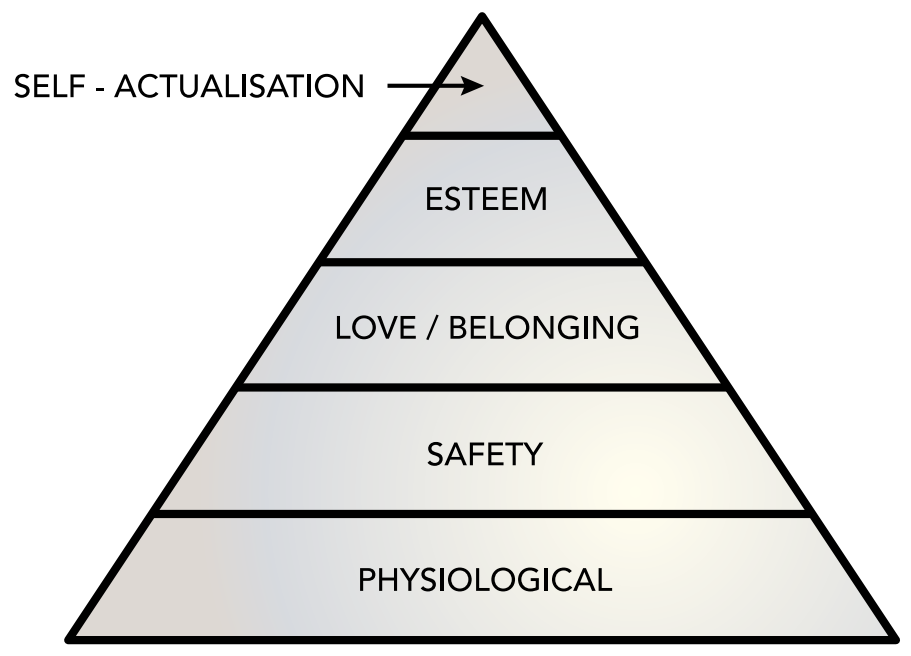

Figure 17: Maslow's Hierarchy of Needs. 
As reported by Walter (2010), a Hierarchy of Needs for UX (Fig. 18) emphasises that 'the interfaces we design must first be functional - they need to solve a problem for us. Next, they need to be reliable - no fail whales please. Our interfaces need to be usable - easy to learn, easy to use, and easy to remember."

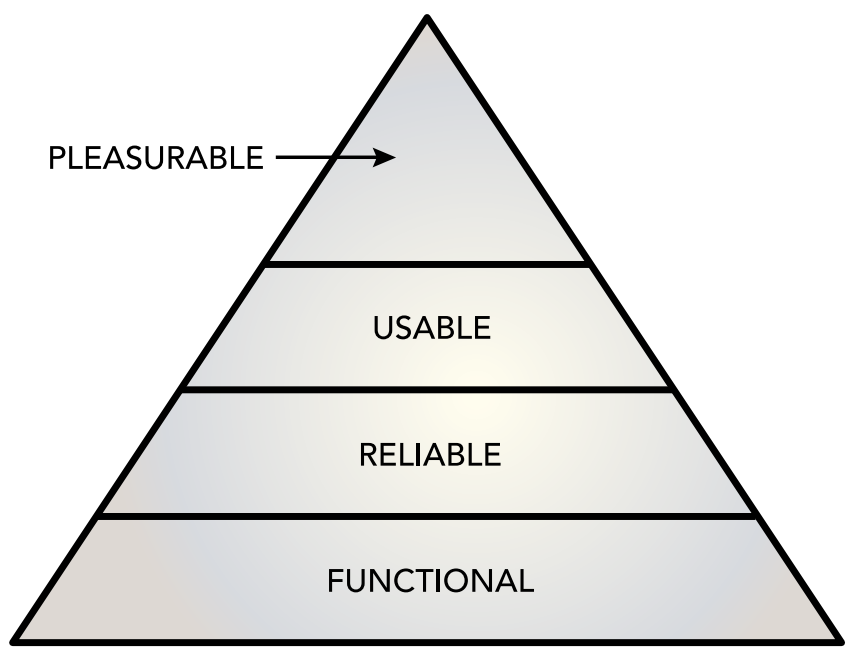

Figure 18: Hierarchy of Needs adapted for the demonstration of needs in user experience.

Similarly to the Maslow's Hierarchy, if any of the needs are insufficiently fulfilled, the person does not feel content. Self-actualisation, defined as 'the realization or fulfilment of one's talents and potentialities, especially considered as a drive or need present in everyone" (Oxford University Press, no date), is essentially a group of positive feelings and actions, such as spontaneity, happiness, self-growth, autonomy, excitement, appreciation, joy, and pleasure. Therefore, the interaction with UI should be enjoyable enough to provoke such positive feelings in a user.

\section{Successful UX significantly increases the user's satisfaction, trust and loyalty, credibility of the brand, enjoyment, and sense of accomplishment}

Undoubtedly, type as a significant, and often crucial, part of the user experience is subjected to emotive response from a user. While the technical requirements, such as legibility, appropriate font size, and leading are relatively easy to measure, the overall success of the interaction is subjected to a level of uncertainty. The type is considered a "sign" or "code", thus semiotic and hierarchical problems might be present; the response is influenced by the user's aesthetic preferences; last but not least, "emotive responses, however, are dependent, somewhat, upon the reader's individual psychological state and social-cultural context" (Jury, 2004: 138). Saltz (2009) argues that "the proper choice of typeface is [... ] essential to the tenor of the message, and it may add to - or, if a poor choice, may detract from - the believability of the text."

Although the "tone of voice" of a UX is important in order to make the user's interaction with the device enjoyable, functionality, reliability, and usability should be granted as much attention. The typographical treatment of the layout, namely right font choices, can aid to establish the desired aesthetic effect. Successful UX significantly increases the user's satisfaction, accessibility of information, trust and loyalty, credibility of the brand, enjoyment, and sense of accomplishment. 


\section{THE PRESENT \& FUTURE OF TRADITIONAL TYPE ON SMALL SCREENS}

From the major part, the future of traditional typefaces and their usage on small-screen displays seems to be defined by the prospective development of internet browsers, applications and UI. Even though the onscreen representation of information has severely improved in past few years, especially with the outbreak of fast and intuitive devices such as Apple iPhone and other smart-phones, the older devices with limited view and UI capability have to be taken into account (Fig. 19).
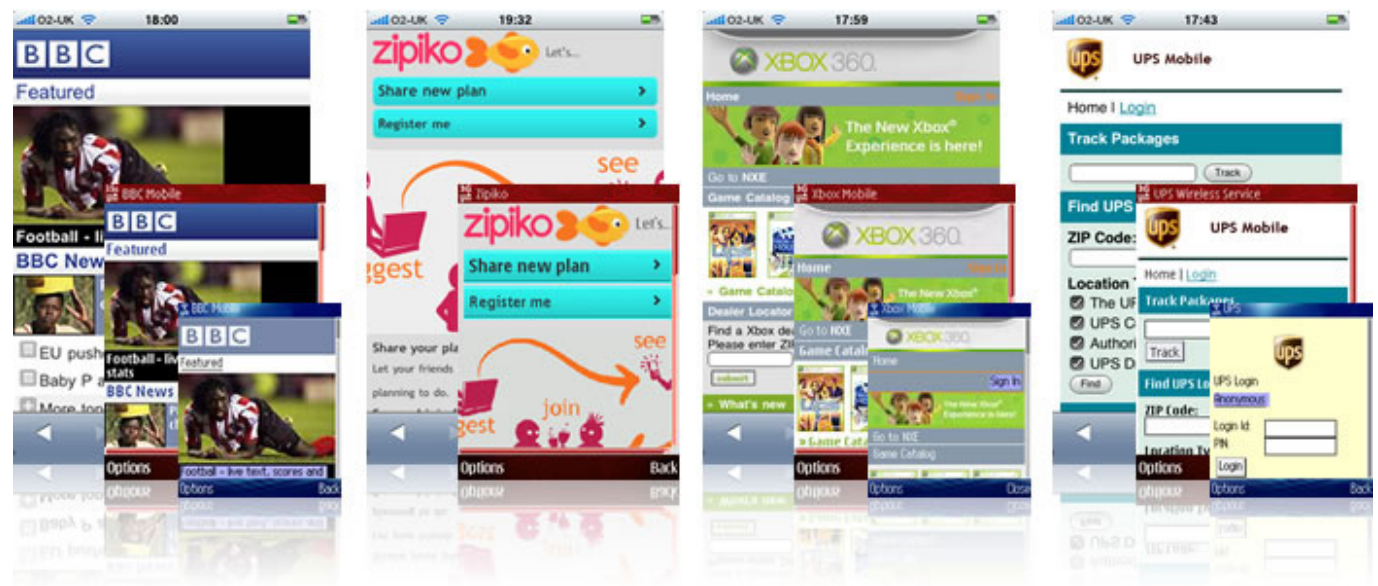

Figure 19: An example of different websites viewed on older devices with various resolutions and CSS browser support.

The release of the Apple iPhone (1st generation) in 2007 has provoked a revolution in treatment of applications for small-screen devices. While their development was limited to only a couple of devices (iPhone and iPod Touch), the UI designers and developers obtained an important advantage - the opportunity to focus on a single device without taking different sizes and resolution of non-Apple devices into consideration. Thus, the rapid expansion of quality Apple-approved applications granted the developers more freedom in the treatment of UI and UX, which could be easily tested.

A significant opportunity for screen fonts emerged when Apple introduced iPhone 4 with its signature Retina Display. Seemingly misleading marketing claims about the extraordinary sharpness, resolution, and vibrancy are recognised as valid when a neuroscientist Bryan Jones states that "Apple's Retina Display adequately represents the resolution at which images fall upon our retina" (Jones, 2010). Thus, a rendered font which is consequently displayed on a Retina Display is able to represent significantly finer design details than a regular phone screen (Fig. 20).
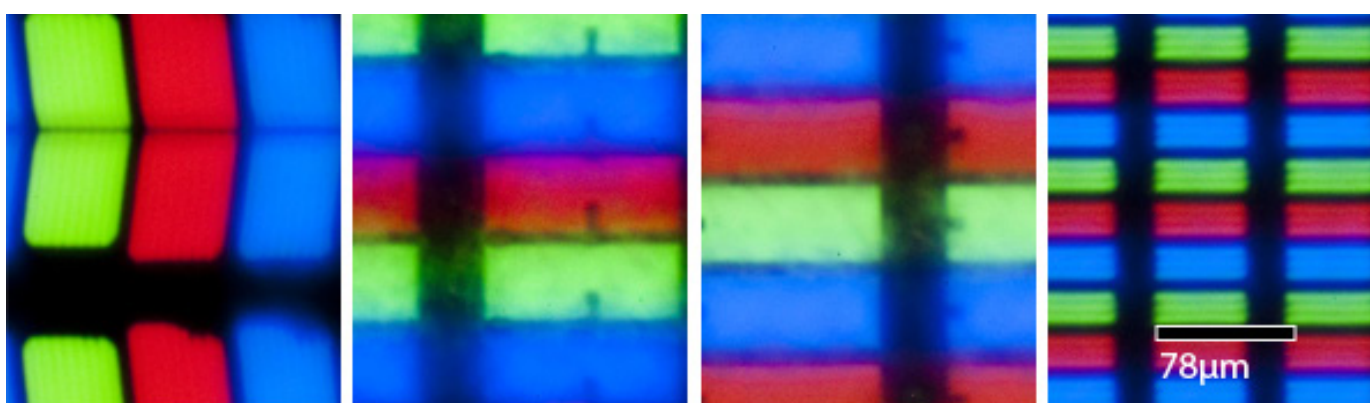

Figure 20: From right to left - pixel density of screens of Apple iPad, iPhone 1G, iPhone $3 \mathrm{G}$ and iPhone $4 \mathrm{G}$ with Retina Display. 
Current development of mobile applications is directed in two directions, web and native apps. Native apps tend to be faster, highly responsive, can be easily connected to, and use the phone hardware such as a camera or microphone, and offer better control over the typefaces and overall layout. Their downsides are the necessity of update downloads, more complicated sharing of content on social networks, the need of approval for official app stores, and the need for specific development platform on the creators' side.

On the other hand, web apps store the data outside the device, and updates and installations are downloaded automatically, and there is no need for the development for multiple platforms (Calore, 2010). Their biggest setback and blessing at the same time, however, seem to be their architectural structure and potential. While not all the browsers represent the data as precisely as intended, "HTML 5 introduces lots of new tags and enhancements for a wide range of features including form controls, APIs, multimedia, structure, database support and faster processing"(Anderson, no date). While not all the enhancements have been fully utilised yet, it is expected that in combination Javascript, especially with updated libraries like jQuery Mobile, web apps will be able to fairly compete with the native apps.

With the introduction of Retina Display and continuous transformation of the web apps are closer towards the functionality of the native apps, it can be expected that the existing typographic and layout limitations will not be as profound as nowadays. The sharpness of Retina Display allows high-detail elements to be used which contributed to improvements in font rendering and display. As web apps, the regularly updated services such as news and social apps tend to inherit the CSS styling from the main website (The Guardian). In the future, it can be expected that the web apps will be able to offer a more pleasurable experience to the user.
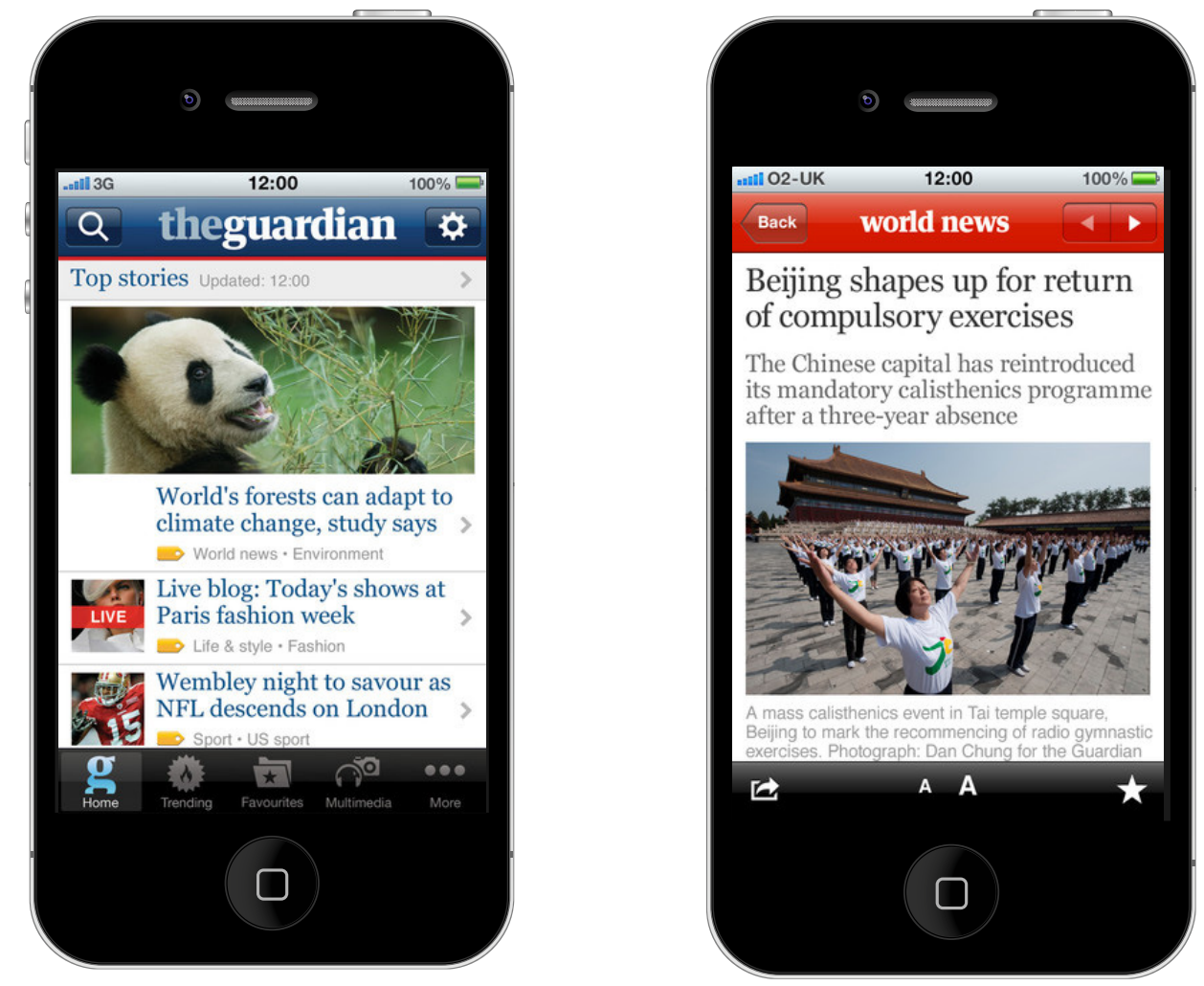

Figure 21, 22 (from left to right): Screenshots of The Guardian app for iPhone/iPod Touch. The Guardian app is web-based and its look is controlled by CSS. 

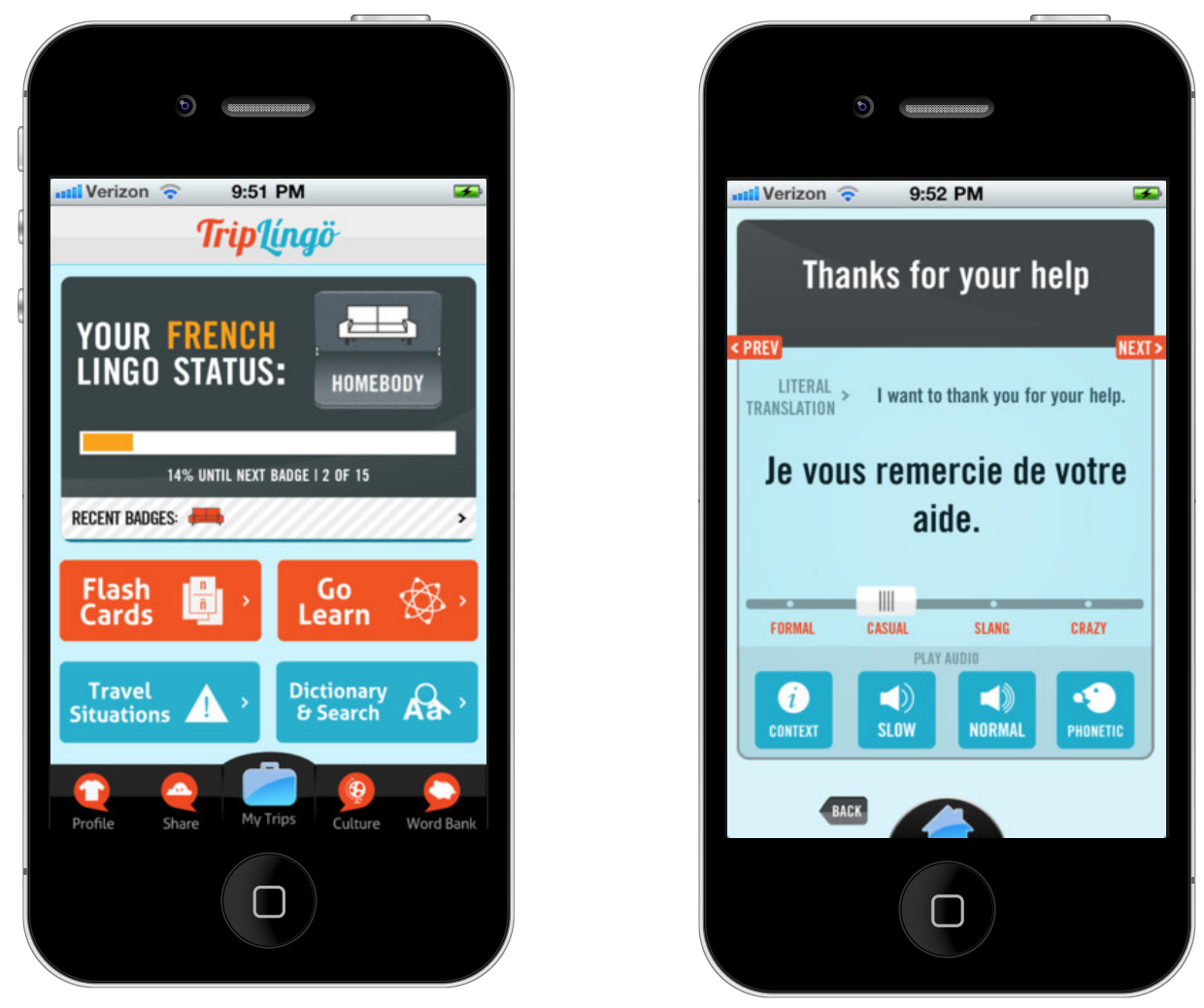

Figure 23, 24 (from left to right): Screenshots of the Trip Lingo app for iPhone/iPod Touch. Native apps allow the designers to experiemnt with typography more than in case of web apps.
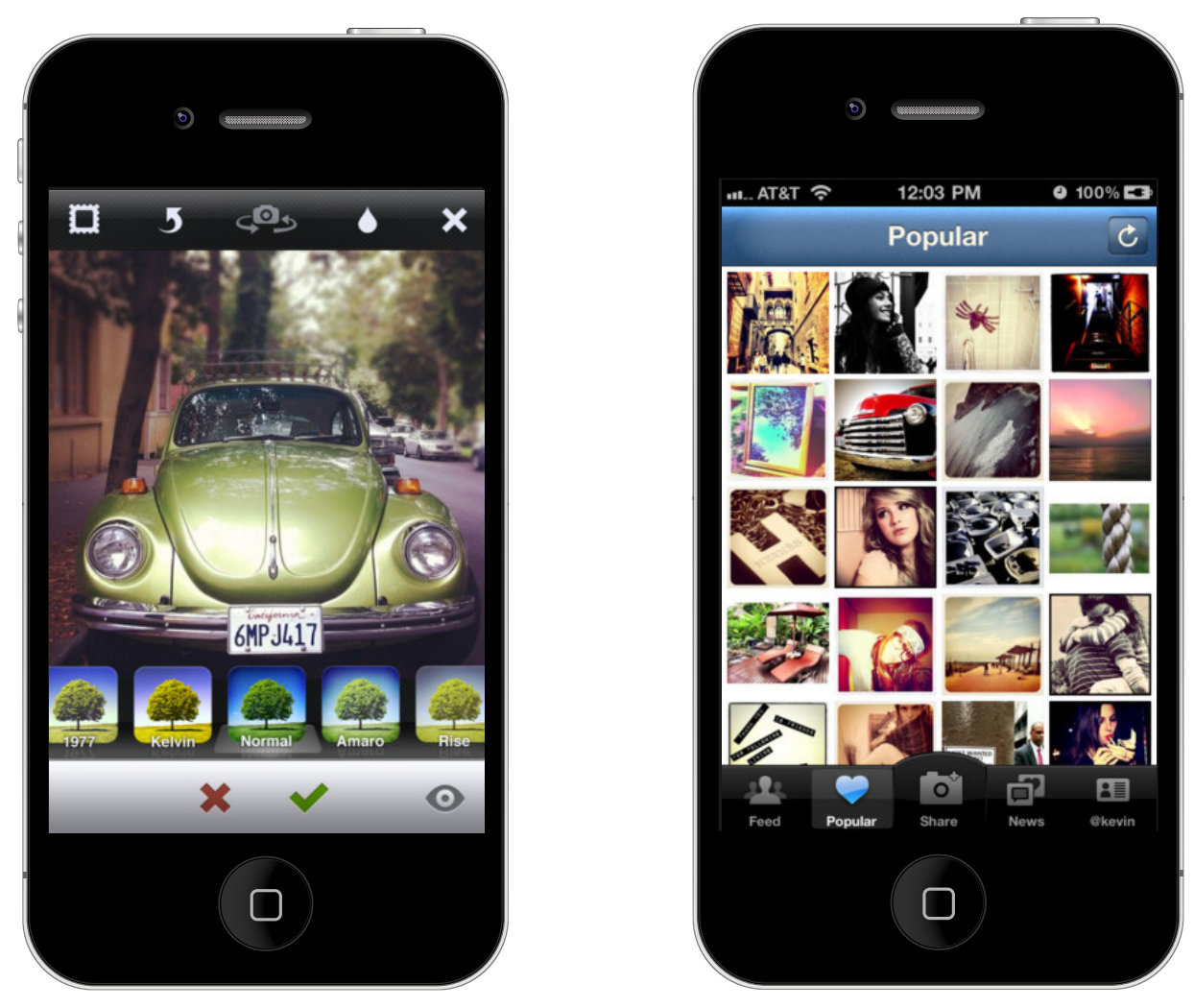

Figure 25, 26 (left to right): Screenshots of Instagram. The combination of photography and social media have helped Instagram to become one of the most popular apps on the App Store. 
Throughout time, the on-going strive for a legible and visually pleasing typeface grew until it reached its peak with the invention of Gutenberg's movable type. The metal movable type became a foundation for further development of typecasting and typesetting. In the centuries following the Gutenberg's invention, the iconic typefaces such as Garamond, Bodoni, Baskerville, and Caslon came into existence. Their popularity still lasts, as their old faces and revivals are being used mainly in print.

Type as a sign communicates not only its literal and connotative meaning; it also has a certain material quality which is expressed by its form. Therefore, the appropriateness of the chosen font to the overall message can either strengthen or weaken the meaning of the word. Moreover, the subjective perception of the sign is tightly connected with the emotive responses of a viewer. The traditional typefaces, however, often carry an aged, sophisticated, historic, or conservative look. As a result, their visual connotation may not cover the desired visual characteristics of a modern user interface design.

An important factor to influence the use of traditional typefaces in a digital environment is a varying screen resolution and different methods of type rendering. The parts of a serif type which require a precise representation, such as serifs and thin strokes, are often distorted. Such deformity negatively influences the readability and legibility on the screen.

The back-lit environment also poses a problem. High contrast levels between the type and background cause undesired optical effects which are even strengthened by the emission of light on the background and additional reflection. E Ink technology used for modern e-readers addresses these problems; the surface of the screen is matte and does not emit any light. Therefore, the reflection is minimal and the feel of reading a hard copy is maintained.

Unlike the traditional serif fonts, screen fonts such as Verdana and Trebuchet MS exhibit characteristics which significantly improve their legibility and readability on digital screens. Generous x-height, wide tracking, wide punch width, and relatively thick, distinctive glyphs contribute to their successful representation in the digital environment. The tools for online font integration, such as Typekit, offer a technological base for usage of fonts outside the default choices; unfortunately, such services still lack a uniform support on small-screen devices.

The future of traditional typefaces in digital media seems to be determined by the technological advancement of mobile technologies. Current innovations, such as the sharpness of Apple's Retina Display, together with developmental progression of web-based apps, might still bring the dawn to the use of traditional typefaces in digital media. 


\section{REFERENCES}

Adobe Systems Incorporated (2009) Type rendering on the web. Available at: http://blog.typekit.com/2010/10/05/ type-rendering-on-the-web/ (Accessed: 2 January 2012).

Ambrose, G. er Harris, P. (2006) The Fundamentals Of Typography. London: Ava Publishing.

Anderson, J. (no date) HTML5 is Here Now! HTML5 Benefits for Users and Developers. Available at: http://janderson99. hubpages.com/hub/HTML5-is-Here-Now-HTML5-Benefits-for-Users-and-Developers (Accessed: 20 December 2011). Anderson, S. P. (2011) Seductive Interaction Design: Creating Playful, Fun, and Effective User Experiences. Berkeley: New Riders. Baines, P. er Haslam, A. (2005) Type and typography, 2nd ed. Laurence King Publishing. Brownie, B. (2009) Semiotics of Typography. Available at: http:/ /www.typedimage.com/SemioticsandTypography.pdf (Accessed: 20 December 2011).

Byrne, J. (2003) Accessible Web Typography - An introduction for web designers. Glasgow: ScotConnect.

Calore, M. (2010) How Do Native Apps and Web Apps Compare?. Available at: http://www.webmonkey.com/2010/08/ how-do-native-apps-and-web-apps-compare/ (Accessed: 4 January 2012)

Carroll, B. (no date) Denotation - Connotation lecture notes outline. Available at: http:/ /www.cubanxgiants.com/ berry/300/outlines/outline4.pdf (Accessed: 20 December 2011).

Chandler, D. (2005) Semiotics for Beginners. Available at: http://www.aber.ac.uk/media/Documents/S4B/sem01.html (Accessed: 26 December 2011).

Cobley, P. (2009) The Routledge Companion to Semiotics. New York: Routledge.

Crow, D. (2010) Visible Signs: An Introduction to Semiotics in Visual Arts, 2nd ed. Lausanne: AVA Publishing SA.

Designhistory.org (2000) Milestones in Typography. Available at: http://designhistory.org/type_milestones.html (Accessed: 16 December 2011).

Drucker, J. (1994) The visible word: experimental typography and modern art, 1909-1923. Chicago: The University of Chicago Press.

Eco, U. (1979) A Theory of Semiotics. Bloomington: Indiana University Press.

Frazier, L. J. (1920) Modern Type Display: A Manual in the Selection and Use of Type er Ornament for Printers er Advertisers. Chicago: L. J. Frazier.

Giannattasio, T. (2009) The Ails Of Typographic Anti-Aliasing. Available at: http:/ /www.smashingmagazine. com/2009/11/02/the-ails-of-typographic-anti-aliasing/ (Accessed: 26 December 2011).

Herrmann, R. (2011) How do we read words and how should we set them?. Available at: http:/ /opentype.info/ blog/2011/06/14/how-do-we-read-words-and-how-should-we-set-them/ (Accessed: 25 October 2011).

Herrmann, R. (2011) What makes letters legible?. Available at: http://opentype.info/blog/2011/08/01/what-makesletters-legible/ (Accessed: 25 October 2011).

Hillner, M. (2009) Basics Typography: Virtual Typography. Lausanne: AVA Publishing SA.

Independent Television Service (2008) The History of Type. Available at: http:/ /www.pbs.org/independentlens/ helvetica/type.html (Accessed: 3 January 2012).

Jones, B. (2010) Apple Retina Display. Available at: http://prometheus.med.utah.edu/ bwjones/2010/06/appleretina-display/ (Accessed: 3 January 2012).

Jury, D. (2004) About face: reviving the rules of typography. Hove: Rotovision.

Kissane, E. (2011) Elements of Content Strategy. New York: Jeffrey Zeldman.

Kolman, S. (2009) A Study of the Typeface, Lowell: University of Massachusetts - Lowell.

Linotype GmbH (no date) JUST WHAT MAKES A "GARAMOND"A GARAMOND?. Available at: http:/ /www.linotype. com/3474/garamondfontfeature.html (Accessed: 2 January 2012). 
Meeker, M., Devitt, S. e Wu, L. (2009) ' Economy + Internet Trends', Web 2.0 Summit. San Francisco, 20th October 2009. Morgan Stanley Research. Available at: http://www.morganstanley.com/institutional/techresearch/pdfs/ MS_Economy_Internet_Trends_102009_FINAL.pdf (Accessed: 29 November 2011).

Nielsen, J. (2006) F-Shaped Pattern For Reading Web Content. Available at: http://www.useit.com/alertbox/reading pattern.html (Accessed: 26 December 2011).

Norman, D. A. (2002) Emotion er Design: Attractive things work better. Available at: http://www.jnd.org/dn.mss/ emotion_design_attractive_things_work_better.html (Accessed: 13 December 2011).

Noth, W. (1990) Handbook of Semiotics. Bloomington: Indiana University Press.

Oxford University Press (no date) Self-actualization. Available at: http:/ /oxforddictionaries.com/definition/selfactualization?q=self-actualisation (Accessed: 3 January 2012).

Rabinowitz, T. (2006) Exploring Typography. Clifton Park: Thomson Delmar Learning.

Saffer, D. (2009) Designing for Interaction: Creating Innovative Applications and Devices. 2nd ed. Berkeley: New Riders. Salen, K. e Zimmerman, E. (2004) Rules of Play. Cambridge: The MIT Press.

Saltz, I. (2009) Typography essentials: 100 design principles for working with type. Minneapolis: Rockport Publishers.

Sanchez, C. A. e Goolsbee, J. Z. (2010) ' Character size and reading to remember from small displays', Elsevier Computers er Education 55, pp. 1056-1062.

Shaugnessy, A. (2005) How To Be a Graphic Designer Without Losing Your Soul. London: Laurence King Publishing.

Shaugnessy, A. (2009) Graphic Design: A User's Manual. London: Laurence King Publishing.

Shaw, P. (2005) The Digital Past: When Typefaces Were Experimental. Available at: http:/ /www.aiga.org/the-digital-pastwhen-typefaces-were-experimental/ (Accessed: 3 December 2011).

Spitzmüller, J. (2007) Visible by Design: The Significance of Typography in Media Communication. Tokyo: Nihon University.

Szafranek, K. (2009) Font Smoothing Explained. Available at: http://szafranek.net/works/articles/font-smoothingexplained/ (Accessed: 29 December 2011).

Walter, A. (2010) Emotional Interface Design: The Gateway to Passionate Users. Available at: http://thinkvitamin.com/ design/emotional-interface-design-the-gateway-to-passionate-users/ (Accessed: 13 December 2011).

Walter, A. (2011) Designing for Emotion. New York: Jeffrey Zeldman.

Weinschenk, S. (2011) 100 Things Every Designer Needs to Know About People. Berkeley: New Riders.

Will-Harris, D. (no date) The Best Faces for the Screen. Available at: http://www.will-harris.com/typoscrn.htm (Accessed: 8 December 2011).

Wroblewski, L. (2009) Mobile First. Available at: http://www.lukew.com/ff/entry.asp?933 (Accessed: 2 December 2011).

Wroblewski, L. (2011) Mobile First. New York: Jeffrey Zeldman.

Zarley, J. (2011) EBook Publication for Training. Purple Palm Media. 
FIGURE 1, P. 8: Sherman, N. (2009) Gutenberg Bible Initial [Online Image]. Available at: http://woodtyper.com/444 (Accessed: 1 December 2011).

FIGURE 2, P. 9: Broadley, J. (2007) History of typography: Old Style [Online Image]. Available at: http:/ / ilovetypography.com/2007/11/21/type-terminology-old-style/ (Accessed: 1 December 2011).

FIGURE 3, P. 9: UXDE Magazine (2011) Garamond [Online Image]. Available at: http://www.lava360.com/fonts / top-10-pro-fonts-to-spark-some-creativity-in-you/ (Accessed: 29 December 2011).

FIGURE 4, P. 12: Isaac, M. (2011) Android Market Growth [Online Image]. Available at: http:/ /www.wired.com/ gadgetlab/2011/12/android-market-downloads/ (Accessed: 15 December 2011).

FIGURE 5, P. 13: Rieger, B. (2011) Effective Design for Multiple Screen Sizes [Online Image]. Available at: http:// mobiforge.com/designing/story/effective-design-multiple-screen-sizes (Accessed: 26 October 2011).

FIGURE 6, P. 13: Silvia Weinzettelova (2012) Scaling of fonts - Bézier curves.

FIGURE 7, P. 13: Brown, T. (2010) Proxima Nova lowercase "a", as rendered by three different browser/OS mixes at 16px [Online Image]. Available at: http://blog.typekit.com/2010/10/05/type-rendering-on-the-web/ (Accessed: 26 November 2011).

FIGURE 8, P. 14: Giannattasio, T. (2009) 42pt "Goudy Oldstyle Bold": aliased and anti-aliased versions [Online Image]. Available at: http://www.smashingmagazine.com/2009/11/02/the-ails-of-typographic-anti-aliasing/ (Accessed: 29 December 2011)

FIGURE 9, P. 14: Giannattasio, T. (2009a) Hinted and unhinted type [Online Image]. Available at: http://www. smashingmagazine.com/2009/11/02/the-ails-of-typographic-anti-aliasing/ (Accessed: 29 December 2011).

FIGURE 10, P. 15: Giannattasio, T. (2009b) Subpixel rendering [Online Image]. Available at: http://www. smashingmagazine.com/2009/11/02/the-ails-of-typographic-anti-aliasing/ (Accessed: 29 December 2011).

FIGURE 11, P. 15: Rabinowitz, T. (2006) "Type Glow", Exploring Typography. Clifton Park: Thomson Delmar Learning FIGURE 12, P. 16: Hume, A. (2005) The Verdana face in detail [Online Image]. Available at: http://www.sitepoint. com/anatomy-web-fonts/ (Accessed: 19 December 2011).

FIGURE 13, P. 16: Hume, A. (2005) The Trebuchet face in detail [Online Image]. Available at: http://www.sitepoint. com/anatomy-web-fonts/ (Accessed: 19 December 2011).

FIGURE 14, P. 16: Hume, A. (2005) The Helvetica face in detail [Online Image]. Available at: http://www.sitepoint. com/anatomy-web-fonts/ (Accessed: 19 December 2011).

FIGURE 15, P. 17: Snook, J. (no date) SNOOK.CA [Online Image]. Available at: http://snook.ca/ (Accessed: 29 December 2011).

FIGURE 16, P. 18: Dick, M. (no date) Snook [Online Image]. Available at: http://cssiphone.com/gallery/page/2 (Accessed: 29 December 2011).

FIGURE 17, P. 18: Silvia Weinzettelova (2012) Maslow's Hierarchy of Needs.

FIGURE 18, P. 19: Silvia Weinzettelova (2012) Hierarchy of Needs for UX.

FIGURE 19, P. 20: Rieger, B. (2011) The 'Problem With Pixels' [Online Image]. Available at: http://mobiforge.com/ designing/story/effetive-design-multiple-screen-sizes (Accessed: 26 October 2011).

FIGURE 20, P. 20: Jones, B. (2010) Apple Retina Display [Online Image]. Available at: http://prometheus.med.utah. edu/ bwjones/2010/06/apple-retina-display/ (Accessed: 19 December 2011).

FIGURE 21 (LEFT), 22 (RIGHT), P. 21: Guardian News er Media Ltd (no date) The Guardian [Online Image]. Available at: http://itunes.apple.com/gb/app/the-guardian/id409128287?mt=8 (Accessed: 8 December 2011).

FIGURE 23 (LEFT), 24 (RIGHT), P. 22: TripLingo LLC (no date) TripLingo French - France [Online Image]. Available at: http://itunes.apple.com/us/app/triplingo-french-france/id434845830?mt=8 (Accessed: 3 January 2012).

FIGURE 25 (LEFT), 26 (RIGHT), P. 22: Burbn Inc. (no date) Instagram [Online Image]. Available at: http://itunes. apple.com/us/app/instagram/id389801252?mt=8 (Accessed: 3 January 2012). 